\title{
Design and effect of performance-based pharmacy payment models
}

\author{
Benjamin Y Urick, PharmD, PhD; Shweta Pathak, PhD; \\ Tamera D Hughes, PharmD, PhD; and Stefanie P Ferreri, PharmD
}

\section{What is already known about this subject}

- Performance-based payment models for community pharmacies have become increasingly commonplace.

- Little research has described the design and effect of these models on pharmacies.

\section{ABSTRACT}

BACKGROUND: Community pharmacy participation in performance-based payment models has increased in recent years. Despite this, there has been neither much research done to evaluate the effect of these models on health care quality and spending nor is there extensive literature on the design of these models.

OBJECTIVES: To (a) describe the types of measures used in performance-based pharmacy payment models (PBPPMs); (b) describe the financial impact of PBPPMs on pharmacies; (3) explore pharmacy owners' perceptions of PBPPMs; and (4) describe any practice changes made in response to PBPPMs.

\section{What this study adds}

- Performance-based pharmacy payment models create confusion, frustration, and financial burden for community pharmacy owners.

- Many pharmacy owners increased service offerings in response to these models.

- Opportunities for improvement in model design include (a) increased payer engagement with pharmacists in model design and measure specification; (b) create opportunities for bonuses as well as penalties; and (c) research on the effect of models on patient care.

METHODS: This is a cross-sectional study that surveyed independent community pharmacy owners between November 2019 and January 2020. The survey included 45 items split into 5 sections that covered respondent characteristics and the 4 domain objectives. Descriptive statistics were used for quantitative responses, and free-text responses were assessed for themes.

RESULTS: Of the 68 individuals who responded to the survey, 42 were community pharmacy owners who met the study eligibility criteria, and 30 responded to most survey items. Owners expressed frustration at the design of PBPPMs, with $90 \%$ stating that they did not feel that the actions necessary to meet or exceed performance standards were

\section{Author affiliations}

Benjamin Y Urick, PharmD, PhD; Shweta Pathak, PhD; Tamera D Hughes, PharmD, PhD; and Stefanie P Ferreri, PharmD, Eshelman School of Pharmacy, University of North Carolina, Chapel Hill.

AUTHOR CORRESPONDENCE:

Benjamin Y Urick, benurick@email.unc.edu

J Manag Care Spec Pharm. 2021;27(3):306-15

Copyright $@ 2021$, Academy of Managed Care Pharmacy. All rights reserved.

within their control, and $90 \%$ also reported a loss of revenue because of these models. In addition, large numbers of respondents felt that they did not have enough information on how performance measures were computed $(76.7 \%)$ or how cut-points were determined

(86.7\%). Despite negative feelings, most owners reported implementing changes in service offerings as a result of these models.

CONCLUSIONS: PBPPMs appear to be commonplace and put substantial financial burden on community pharmacies. Study results suggest that greater education by payers could improve pharmacist engagement, as could involvement of pharmacies in the design and maintenance of PBPPMs. 
In response to rising health care costs and lackluster quality of care, payers in the United States have implemented performance-based payment models that seek to reduce spending and improve quality by linking payment to performance. ${ }^{1,2}$ While performance-based payment models have become the standard for U.S. health care payments, evidence for the effect of these alternative payment models on health care quality and spending is mixed. ${ }^{2-4}$ Well-designed studies of pay-for-performance models implemented in ambulatory care settings have found that physicians respond to incentives and can improve indicators of care quality over the short term, ${ }^{5-7}$ but the effect of these models on health outcomes and spending has not been consistently demonstrated..$^{3,4,8-10}$ Evidence from theory and practice suggests that elements which support success within performancebased payment models include incentives targeted at individuals (e.g., physicians) as well as groups (e.g., physician group practices), use of penalties (i.e., downside risk) as well as bonuses (i.e., upside risk), aligned incentives between payers and providers, flexibility to change over time, and engagement with providers in the design process. ${ }^{2-4,9}$

Despite the movement toward performance-based payments in the broader health care system, payments to pharmacies have remained primarily fee-for-service without consideration for quality or performance. This is beginning to change, however. For example, more than 42 million patients are in a performance-based program managed by pharmacists through the Electronic Quality Improvement Platform for Plans and Pharmacists (EQuIPP). ${ }^{11}$

To date, much of the expansion of performance-based pharmacy payment models (PBPPMs) has been led by Medicare Part D plan sponsors and their pharmacy benefit managers (PBMs). The typical Medicare Part D PBPPM uses quality measures, frequently derived from the Medicare Star Ratings Program, to determine the direct and indirect remuneration (DIR) fees (i.e., charges to pharmacy outside of administration fees not captured at the point of sale) owed by the pharmacy on a quarterly or annual basis. ${ }^{12,13}$ DIR fees paid by pharmacies to Medicare Part D plan sponsors have grown tremendously in recent years, from $\$ 0.2$ billion in 2013 to $\$ 9.1$ billion in $2019 .{ }^{14}$ Interestingly, in reports of DIR fees, it is noted that although it is possible for pharmacies to receive bonuses even some top performers are assessed DIR fees. ${ }^{15}$

Little research has evaluated the effect of these models on health care quality and spending. A cross-sectional study of an early pharmacy pay-for-performance program implemented by Inland Empire Health Plan in California found that pharmacies voluntarily participating in the program had performance that was equal to or worse than pharmacies that did not participate. ${ }^{16}$ An observational difference-in-differences analysis of the effect of enhanced community pharmacy services on Medicaid enrollees in North Carolina found that an alternative payment model improved adherence but did not affect health care utilization or spending. ${ }^{17}$

There is anecdotal evidence that pharmacists have become increasingly frustrated with the design and implementation of PBPPMs, as well as with the DIR fees mechanism used to levy performance-based penalties. The recent growth in DIR fees has caused many community pharmacy leaders to become disillusioned with the concept of performance-based payments. ${ }^{18-20}$

Theoretically, models such as DIR-driven PBPPMs, where bonuses are rare and the link between performance and payment is unclear, reduce provider engagement and are less effective at creating practice change. ${ }^{2}$ In addition, it is a common belief that DIR fees lead to pharmacy closures, particularly for pharmacies located in socially disadvantaged and rural areas. ${ }^{21}$ However, obtaining objective information on the design and effect of PBPPMs is challenging, given the proprietary nature of contracts between third-party payers and pharmacies or the pharmacy services administrative organizations (PSAOs) that represent them in contracting.

To better understand PBPPMs, the objective of this study was to explore pharmacy owners' perceptions of PBPPMs, including measures used to assess performance, financial impact, and implications for practice changes. Results of this study will be useful in understanding the implementation of PBPPMs outside of Medicare Part D, as well as in identifying PBPPM components that can be targeted for improving alternative pharmacy payment models.

\section{Methods}

\section{SURVEY DISTRIBUTION}

This study used a cross-sectional survey that was distributed to a convenience sample of community pharmacy owners who were members of the Community Pharmacy Enhanced Services Networks (CPESN) in Iowa, North Carolina, Mississippi, and Georgia, as well as members of the National Community Pharmacy Association (NCPA) for the year 2019-2020. The survey was developed using Qualtrics version January 2020 (C) 2019-2020 (Qualtrics, Provo, UT), and invitations to the survey were distributed electronically via email by the CPESN networks and NCPA as a part of regular communications (e.g., weekly newsletters) or as a direct communication with an invitation to the study.

As a result of this pragmatic distribution method, the exact number of potential participants to whom surveys were sent cannot be determined. Community pharmacy 
owners were targeted because of their exposure to the financial risk of the pharmacy, as well as their ability to implement new services and workflow to respond to the incentives and performance goals created by PBPPMs. CPESN networks were chosen as a partner for distributing this survey because of the large number of progressive independent pharmacies that participate in their networks, and the 4 networks included in this study were identified as mature networks with actively participating pharmacies. NCPA was chosen because it is the largest advocacy organization representing the interests of community pharmacy owners.

Participants accessed and completed the survey between November 20, 2019, and January 17, 2020. Ownership of a community pharmacy and participation in value-based contracting with a payer was a requirement to be eligible for survey participation. A monetary incentive for survey participation was provided to encourage higher response rates. ${ }^{22}$ This study was approved by the authors' institutional review board (IRB \#19-0093).

\section{SURVEY DESIGN}

The survey instrument was drafted by adapting instruments from the existing literature,$^{23}$ previous work by the authors ${ }^{24}$ and expert guidance from NCPA. The survey was pilot-tested with a convenience sample of 6 community pharmacists and community pharmacy owners to ensure the face and content validity of survey items.

The final survey had 45 items split among 5 sections (Supplementary Materials, available in online article). These sections gathered information on (1) the characteristics of the owners (e.g., whether they were licensed pharmacists), the number of owned pharmacies, pharmacy setting, and the operational characteristics of the owned pharmacies; (2) owners' experience with PBPPMs using a combination of binary responses (yes/no) and multiple-choice questions regarding PBPPM contracts, including the types of performance measures in use and the financial impact of PBPPMs; (3) owners' response to PBPPMs through a series of multiple-choice items; (4) owners' perception using a 5-point Likert scale (strongly agree, somewhat agree, neutral, somewhat disagree, and strongly disagree), which was later summarized using 3 categories (agreed, neutral, and disagree); and (5) overall impressions regarding PBPPMS using free-text responses.

Descriptive statistics using counts and percentage frequencies were used to assess survey responses. Also, free-text responses were assessed to provide additional context regarding PBPPMs. Data for this survey were analyzed using SAS version 9.4 (SAS Institute, Cary, NC).

\section{Results}

Of the 68 individuals who responded to the survey, 42 were community pharmacy owners who met the study eligibility criteria. Of these eligible participants, 30 responded to most survey items. Thus, our completion rate among responders was $71.4 \%$. While a small number of owners were not pharmacists (3.4\%), a majority of the participating community pharmacy owners were licensed pharmacists holding licensure for more than 20 years (67.9\%; Table 1). Approximately $72 \%$ of the pharmacies owned by participants belonged to CPESN, indicating their interest in engaging with an organization aimed at improving the quality of services provided by community pharmacies. Two thirds (68\%) of the owners reported that their pharmacies employed 1 pharmacist for managing both clinical and dispensing responsibilities, while $18 \%$ reported having a pharmacist dedicated to managing only clinical responsibilities with little to no dispensing responsibilities. In addition, respondents indicated that their pharmacies employed pharmacy students (58.6\%), but relatively few (10.3\%) employed pharmacy residents.

\section{TYPES OF MEASURES USED BY PAYER}

Performance measures in PBPPMs were reported largely for Medicare $(n=29)$, followed by commercial payers $(n=12)$ and Medicaid ( $\mathrm{n}=8$; Table 2). Measures commonly reported for Medicare were medication adherence (96.7\%) and inappropriate use measures, such as statin use in persons with diabetes (96.7\%), high-risk medications in the elderly (76.7\%), and angiotensin-converting enzyme inhibitor (ACE-I)/angiotensin receptor blocker (ARB) in persons with diabetes and hypertension (96.7\%). Other measures used frequently in Medicare were dispensing-based measures such as formulary compliance rate (74.1\%), generic effective rate (69.2\%), and generic drug utilization rate (77.8\%). Cost and utilization-based performance measures, such as health care spending (16.7\%) and hospitalization rates (12\%) were used less frequently in Medicare. Like Medicare, Medicaid, and commercial payers' frequent use of adherence, inappropriate use, and dispensing-based measures for assessing pharmacy performance were reported, whereas utilization and cost-based measures were less commonly reported. Additional measures, such as medication therapy management completion rate and lowering risk score, were noted in Medicare, while contract rates from pharmacy services administrative organizations were noted for commercial contracts as free-text responses.

\section{FINANCIAL IMPACT OF PBPPMS}

Only some owners (26.7\%) reported directly participating in the PBPPM contracting process (Table 1). While 10\% of 


\section{TABLE 1 Characteristics of Participating Pharmacy Owners and Their Pharmacies}

\begin{tabular}{|c|c|c|}
\hline Description & Categories & $\%(n)$ \\
\hline \multicolumn{3}{|l|}{ Characteristics of survey participants } \\
\hline Licensed pharmacist & Yes & $96.6(28)$ \\
\hline \multirow[t]{4}{*}{ Years licensed pharmacist } & $0-10$ & 14.3 \\
\hline & $11-20$ & $17.9 \quad(5)$ \\
\hline & $21-30$ & $53.6 \quad(15)$ \\
\hline & $>30$ & 14.3 \\
\hline Participated in the contracting process for PBPPM & Yes & $26.7 \quad(8)$ \\
\hline \multicolumn{3}{|l|}{ Characteristics of pharmacies owned by participants } \\
\hline \multirow[t]{2}{*}{ Pharmacy setting } & Retail & $69.0(20)$ \\
\hline & Other + Retail & $31.0 \quad(9)$ \\
\hline \multirow[t]{3}{*}{ Number of licensed pharmacies with ownership stake } & 1 & $48.3 \quad(14)$ \\
\hline & 2 & $27.6 \quad(8)$ \\
\hline & $>2$ & $24.1 \quad(7)$ \\
\hline \multirow[t]{3}{*}{ Average weekly prescription fills } & $0-750$ & $62.1(18)$ \\
\hline & $751-1,500$ & 31.0 \\
\hline & $>1,500$ & 6.9 \\
\hline Part of CPESN & Yes & $72.4 \quad(21)$ \\
\hline $\begin{array}{l}\text { Dedicated full- or part-time pharmacists for clinical responsibilities } \\
\text { only (i.e., little to no dispensing responsibilities) }\end{array}$ & Yes & 17.9 \\
\hline $\begin{array}{l}\text { Only } 1 \text { pharmacist works at a time managing both dispensing and } \\
\text { clinical responsibilities }\end{array}$ & Yes & $67.9 \quad(19)$ \\
\hline Technicians devoted to clinical service duties & Yes & $65.5(19)$ \\
\hline $\begin{array}{l}\text { Two or more pharmacists are scheduled at the same time (overlap) to } \\
\text { allow at least } 1 \text { pharmacist to complete clinical responsibilities outside } \\
\text { of dispensing workflow }\end{array}$ & Yes & $42.9 \quad(12)$ \\
\hline $\begin{array}{l}\text { Two or more pharmacists work at the same time completing clinical } \\
\text { responsibilities within dispensing workflow as time allows } \\
\text { (e.g., integrated with dispensing) }\end{array}$ & Yes & $39.3(11)$ \\
\hline \multirow[t]{5}{*}{ Incorporating residents } & Residency rotation & $3.4 \quad(1)$ \\
\hline & Neither; we do not have pharmacy residents & $89.7 \quad(26)$ \\
\hline & Employed throughout the year & $0.0 \quad(0)$ \\
\hline & Both employment and residency rotation & 6.9 \\
\hline & Experiential rotation & 20.7 \\
\hline \multirow[t]{3}{*}{ Incorporating students } & Neither; we do not have student pharmacists & 41.4 \\
\hline & Employed throughout the year & 10.3 \\
\hline & Both employment and experiential rotation & 27.6 \\
\hline
\end{tabular}

Note: Total number of responses for each item range from 28 to 29.

CPESN=Community Pharmacy Enhanced Services Networks; PBPPM=performance-based pharmacy payment models.

pharmacy owners indicated a flat fee-based (a fixed rate, such as $\$ 3$, per prescription is taken away or rewarded) incentive structure for determining payments in their PBPPM contracts, $57 \%$ of owners indicated a percentage-based (i.e,. a fixed percentage, such as $2 \%$, is taken away or rewarded) incentive structure for determining payments. Most owners (73.3\%) reported that current PBPPMs were punitive in nature (Table 3 ). None of the participants $(0 \%)$ stated gaining 


\section{TABLE 2 Types of Measures Used by Payer}

\begin{tabular}{|c|c|c|c|c|c|c|c|}
\hline \multirow{3}{*}{$\begin{array}{l}\text { Measure Type } \\
\text { Medication adherence }\end{array}$} & \multicolumn{2}{|c|}{ Medicare } & \multicolumn{3}{|c|}{ Medicaid } & \multicolumn{2}{|c|}{ Commercial } \\
\hline & $\%(n)$ & \multirow{2}{*}{$\begin{array}{c}\begin{array}{c}\text { Total } \\
\text { Responses }\end{array} \\
30\end{array}$} & \multicolumn{2}{|l|}{$\%(n)$} & \multirow{2}{*}{$\begin{array}{c}\begin{array}{c}\text { Total } \\
\text { Responses }\end{array} \\
8 \\
\end{array}$} & $\%(n)$ & \multirow{2}{*}{$\begin{array}{c}\begin{array}{c}\text { Total } \\
\text { Responses }\end{array} \\
12\end{array}$} \\
\hline & $96.7(29)$ & & 50.0 & (4) & & $83.3(10)$ & \\
\hline High-risk medications in the elderly & $76.7(23)$ & 30 & 37.5 & (3) & 8 & $54.5 \quad(6)$ & 11 \\
\hline Statin use in persons with diabetes & $96.7(29)$ & 30 & 50.0 & (4) & 8 & 81.8 & 11 \\
\hline ACE-I/ARB in persons with diabetes and hypertension & 96.7 (29) & 30 & 50.0 & (4) & 8 & 81.8 & 11 \\
\hline Formulary compliance rate & $74.1(20)$ & 27 & 0.0 & $(0)$ & 0 & 62.5 & 8 \\
\hline Generic effective rate ${ }^{a}$ & $69.2(18)$ & 26 & 40.0 & $(2)$ & 5 & 87.5 & 8 \\
\hline Generic drug utilization rate ${ }^{b}$ & $77.8(21)$ & 27 & 71.4 & $(5)$ & 7 & 66.7 & 9 \\
\hline Health care spending & $16.7 \quad(4)$ & 24 & 0.0 & $(0)$ & 0 & 12.5 & 8 \\
\hline Hospitalization rates & 12.0 & 25 & 0.0 & $(0)$ & 0 & 12.5 & 8 \\
\hline Emergency department visit rates & 12.0 & 25 & 0.0 & $(0)$ & 0 & 12.5 & 8 \\
\hline Not aware & $9.1 \quad(1)$ & 11 & 50.0 & $(2)$ & 4 & 50.0 & 4 \\
\hline
\end{tabular}

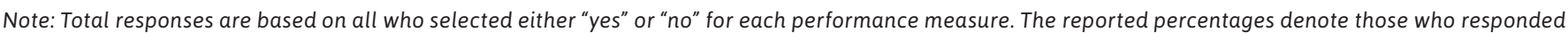
"yes" for each selection.

${ }^{a} A$ contractual rate for reimbursement on generic drug claims.

${ }^{b}$ Percentage of all prescriptions dispensed that are generics.

$A C E-I=$ angiotensin-converting enzyme inhibitor; $A R B=$ angiotensin receptor blocker .

any money through these models, but 90\% described losing money. Notably, $6.7 \%$ of the respondents claimed not knowing the financial impact of these models on the pharmacies they owned, while 3.3\% neutral stated that these models had neither a positive or negative effect on their pharmacy's financial performance. Of those who reported losing money, 51.9\% stated that the amount lost was greater than 100,000 U.S. dollars (USD).

\section{PHARMACY OWNERS' OPINIONS ON PBPPMS}

A majority of community pharmacy owners believed that performance measures used for assessing performance were not meaningful (51.7\%) and that the method used for assessing pharmacy performance was inaccurate $(86.7 \%$; Table 4). Most pharmacy owners thought that pharmacists should not be responsible for ensuring patient adherence to medication $(60 \%)$ but were divided (33\% each agreed, disagreed, or stayed neutral) on whether pharmacists should be responsible for ensuring that patients were on schedule for immunizations. A vast majority of owners believed that performance-based payments were not good for the financial stability (86.7\%) of their pharmacies and that their pharmacies were not on a level playing field for achieving high performance-based ratings (90\%). Also, most owners felt that the actions necessary to meet or exceed performance standards were not within their control (90\%).
Most free-text responses suggested a strong negative sentiment toward PBPPMs. Responses suggested that the current DIR fee structures mostly benefited PBMs and threatened pharmacy sustainability and long-term survival. For example, a participant stated that the current fee structure was "rigged for failure," while another stated that the models would "force the majority of independent pharmacies to close." However, some participants took a more tempered approach, describing PBPPMs as a "necessary evil" and that they "needed [appropriate incentives] to be worth doing."

\section{CHANGES IMPLEMENTED IN RESPONSE TO PBPPMS}

Most community pharmacy owners indicated that they expanded at least 1 existing service in their pharmacies in response to PBPPMs in the previous 12 months, but very few reported implementing new services (Table 5). Examples of expanded services reported by owners included comprehensive medication reviews (58.6\%), synchronized medication fills (62.1\%), telephone reminders to refill prescriptions $(44.8 \%)$, and increased time devoted to patient care (24.1\%), as well as medication dispensing services (31.0\%). Notably, many owners indicated that their pharmacies did not offer patient education-based services such as disease state educational programming $(51.7 \%)$ or educational pamphlets or printouts (31.0\%). 


\section{TABLE 3}

Financial Impact of PerformanceBased Payment Models in Community Pharmacies

\begin{tabular}{|c|c|}
\hline Categories & $\%(n)$ \\
\hline \multicolumn{2}{|l|}{ Incentive type } \\
\hline Most models are punitive & $73.3(22)$ \\
\hline Most models are reward based & $3.3 \quad(1)$ \\
\hline $\begin{array}{l}\text { Most models use a mix of punishments } \\
\text { and rewards }\end{array}$ & $20 \quad(6)$ \\
\hline $\begin{array}{l}\text { I do not have enough information to know } \\
\text { what kind of incentives are most common }\end{array}$ & $3.3(1)$ \\
\hline \multicolumn{2}{|l|}{ Financial impact } \\
\hline Positive (I have gained money) & $0.0 \quad(0)$ \\
\hline $\begin{array}{l}\text { Neutral (There have been no major gains } \\
\text { or losses) }\end{array}$ & $3.3 \quad(1)$ \\
\hline Negative (I have lost money) & $90.0(27)$ \\
\hline $\begin{array}{l}\text { I do not know the financial impact of these } \\
\text { models }\end{array}$ & $6.7 \quad(2)$ \\
\hline \multicolumn{2}{|l|}{ Of those who lost money, the amount lost } \\
\hline$\$ 1-\$ 25,000$ & $7.4 \quad(2)$ \\
\hline$\$ 25,001-\$ 50,000$ & $14.8 \quad(4)$ \\
\hline$\$ 50,001-\$ 75,000$ & $7.4 \quad(2)$ \\
\hline$\$ 75,001-\$ 100,000$ & $18.5 \quad(5)$ \\
\hline More than $\$ 100,000$ & $51.9(14)$ \\
\hline
\end{tabular}

\section{Discussion}

This study found that while PBPPMs were commonly reported for Medicare plans, participants reported that they are now being adopted by commercial and Medicaid plans, as well. Clinically related measures, including medication adherence, high-risk medications in the elderly, statin use in persons with diabetes, and ACE-I/ARB in persons with diabetes and hypertension were common in models across all 3 payers. Also, respondents indicated that measures which are more financially driven (i.e., formulary compliance rate and generic drug utilization rate) are common. Outcome measures, including health care spending, hospitalization rates, and emergency department visit rates, were less common.

The financial burden from PBPPMs on pharmacies appears to be quite high, with more than half of the owners reporting losses greater than 100,000 USD. This amount is equivalent to 2 full-time pharmacy technicians or more than a half a pharmacist full-time equivalent annually. ${ }^{25,26}$
Nearly all participants reported that these models use penalties alone or a mix of penalties and bonuses, and 90\% of participants have lost money as a result of these models. Nearly as many (86.7\%) felt that these payments negatively affected their financial stability but that the actions needed to meet or exceed performance thresholds were not within their control (90\%) and that their pharmacies were not on a level playing field (90\%). This clear expression of frustration in the quantitative results is reflected in the qualitative findings, with respondents stating that these models are "rigged for failure" and will "force the majority of pharmacies to close."

Respondent opinion on performance measures was varied and polarized. When asked if most performance measures assessed meaningful patient outcomes, $41.4 \%$ agreed; $51.7 \%$ disagreed; and only $6.9 \%$ were neutral. The use of adherence measures received low support from respondents, with only $26.7 \%$ agreeing that pharmacists should be responsible for ensuring adherence and $16.7 \%$ agreeing that data from prescription drug claims is an accurate method to evaluate pharmacy performance.

The most support was observed for use of high-risk medications $(60 \%)$ and statin use in persons for diabetes (60\%). This finding is somewhat counterintuitive, in that pharmacists need to contact a prescribing provider to initiate a statin prescription or to evaluate appropriate discontinuation of a high-risk medication, but adherence can be affected without any prescriber communication and therefore may be more within a pharmacist's control. One reason for this discrepancy may be due to lack of pharmacists' confidence in their ability to affect adherence in a meaningful way, since adherence can be affected by several factors beyond a pharmacist's control, ${ }^{27}$ while contacting prescribers regarding discontinuation of high-risk medications or initiating a statin is a tangible action that is likely to improve care outcomes. ${ }^{28}$ Another reason may be due to the opaque nature of the calculation for adherence. Evaluating the presence or absence of a statin or high-risk medication is straightforward, but understanding adherence requires understanding the proportion of days covered algorithm. This lack of understanding would likely lead to mistrust, but this hypothesis cannot be fully evaluated with the data from this survey.

In addition to medication-related measures, the survey found mixed support for immunizations, with equal numbers of respondents in favor of, neutral to, and opposed to pharmacist responsibility for immunizations. Immunizationrelated measures are rarely used in PBPPMs and were not reported in free text by any respondent. This suggests that there may be support for payers adding immunizations as a performance measure, something which a few payers are 


\section{TABLE 4 Opinion of Pharmacy Owners on PBPPMs}

\begin{tabular}{|c|c|c|c|}
\hline \multirow[b]{2}{*}{ Description of Statements } & Agree & Neutral & \multirow{2}{*}{$\begin{array}{c}\text { Disagree } \\
\%(n)\end{array}$} \\
\hline & $\%(n)$ & $\%(n)$ & \\
\hline $\begin{array}{l}\text { Most performance measures used by third-party payers to support PBPPMs } \\
\text { measure meaningful patient outcomes. }\end{array}$ & $41.4(12)$ & $6.9 \quad(2)$ & $51.7(15)$ \\
\hline The methods used to evaluate my pharmacy's performance are accurate. & $6.7 \quad(2)$ & $6.7 \quad(2)$ & $86.7(26)$ \\
\hline $\begin{array}{l}\text { Data from prescription drug claims can be accurately used to evaluate my } \\
\text { pharmacy's performance. }\end{array}$ & $16.7 \quad(5)$ & $3.3(1)$ & $80.0(24)$ \\
\hline $\begin{array}{l}\text { Pharmacists should be responsible for ensuring that patients are adherent to their } \\
\text { medications. }\end{array}$ & $26.7 \quad(8)$ & $13.3 \quad(4)$ & $60.0(18)$ \\
\hline $\begin{array}{l}\text { Pharmacists should make recommendations for discontinuation or alternate } \\
\text { therapy or attempt to switch elderly patients from high-risk medications. }\end{array}$ & $60.0(18)$ & $20 \quad(6)$ & $20.0 \quad(6)$ \\
\hline $\begin{array}{l}\text { Pharmacists should make recommendations that adhere to treatment guidelines } \\
\text { for use on attempt to initiate a statin prescription for patients with diabetes. }\end{array}$ & $60.0(18)$ & 10.0 & $30.0 \quad(9)$ \\
\hline $\begin{array}{l}\text { Pharmacists should be responsible for ensuring that patients are on schedule for } \\
\text { immunizations. }\end{array}$ & $33.3(10)$ & $33.3(10)$ & $33.3(10)$ \\
\hline Reaching performance thresholds set by third parties is good for my patients. & $40.0(12)$ & $13.3 \quad(4)$ & $46.7(14)$ \\
\hline $\begin{array}{l}\text { I have adequate information about how performance measures are computed for } \\
\text { most of the contracts my pharmacy has signed. }\end{array}$ & $16.7 \quad(5)$ & $6.7 \quad(2)$ & $76.7(23)$ \\
\hline $\begin{array}{l}\text { I have adequate information about how third-party payers set the cut-points for } \\
\text { incentives or penalties. }\end{array}$ & $6.7 \quad(2)$ & $6.7 \quad(2)$ & $86.7(26)$ \\
\hline I support having some of my pharmacy's reimbursement tied to its performance. & $30.0 \quad(9)$ & $23.3(7)$ & $46.7(14)$ \\
\hline The use of performance-based payments or fees is good for my patients. & $16.7 \quad(5)$ & $26.7 \quad(8)$ & $56.7(17)$ \\
\hline $\begin{array}{l}\text { The use of performance-based payments or fees is good for my pharmacy's } \\
\text { financial stability. }\end{array}$ & $6.7 \quad(2)$ & $6.7 \quad(2)$ & $86.7(26)$ \\
\hline Pharmacies are on a level playing field for achieving high ratings. & $10.0 \quad(3)$ & $0.0 \quad(0)$ & $90.0(27)$ \\
\hline $\begin{array}{l}\text { The actions necessary to meet or exceed performance cut-points are within my } \\
\text { control. }\end{array}$ & $3.3 \quad(1)$ & $6.7 \quad(2)$ & $90.0(27)$ \\
\hline
\end{tabular}

Note: Total number of responses for each item range from 29 to 30.

PBPPM = performance-based pharmacy payment model.

already doing. Also, a recent report from Pharmacy Quality Solutions found strong support for contracting with payers on outcome measures such as blood pressure, hemoglobin A1c, and cholesterol, as well as substantial capacity for direct collection of relevant clinical data elements. ${ }^{29}$ While building capacity to collect, store, and transmit these clinical elements may take time, ${ }^{29}$ it could be beneficial for progressive payers to consider innovative contracts that include these outcome measures in combination with existing process-type measures.

Responses also indicate substantial opportunity for additional education on model design and measures used in the models. Only $16.7 \%$ of respondents agreed that they had adequate information about how performance measures are computed, and even fewer-6.7\%-indicated that they had adequate information about how third parties set cut-points for incentives or penalties. Despite this lack of understanding and the feeling that models jeopardized the financial stability of pharmacies, $30 \%$ of respondents still supported having some of their pharmacies' reimbursement tied to performance. Evidence suggests that performancebased payment models, which better engage providers in their design, communicate goals prospectively, and creating predictability in performance-based payments, have improved provider engagement and a greater likelihood for success. ${ }^{2}$ Evidence from existing literature suggests that payers may find that additional educational efforts aimed at pharmacies, as well as direct engagement with pharmacists in the design and maintenance of these models, may reduce confusion and improve pharmacists' willingness to participate. ${ }^{2,4}$

In addition, the number of clinically relevant performance measures reported by participants was relatively small. A narrowly focused set of measures may incentivize 


\section{TABLE 5 Implemented or Expanded Services}

\begin{tabular}{|c|c|c|c|c|}
\hline \multirow{3}{*}{$\begin{array}{l}\text { Type of Service } \\
\text { Telephone reminders to refill prescriptions }\end{array}$} & \multirow{2}{*}{$\begin{array}{c}\begin{array}{c}\text { Expanded Existing } \\
\text { Service }\end{array} \\
\%(n) \\
\end{array}$} & \multirow{2}{*}{\begin{tabular}{|c|}
$\begin{array}{c}\text { Implemented New } \\
\text { Service }\end{array}$ \\
$\%(n)$ \\
\end{tabular}} & \multirow{2}{*}{\begin{tabular}{|c|}
$\begin{array}{c}\text { Offered But Didn't } \\
\text { Expand }\end{array}$ \\
$\%(n)$ \\
\end{tabular}} & \multirow{2}{*}{$\begin{array}{c}\begin{array}{c}\text { Did } \\
\text { Not Offer }\end{array} \\
\%(n) \\
\end{array}$} \\
\hline & & & & \\
\hline & $44.8 \quad(13)$ & 0.0 & $44.8 \quad(13)$ & 10.3 \\
\hline Medication home delivery & $39.3 \quad(11)$ & 0.0 & 50.0 & 10.7 \\
\hline $\begin{array}{l}\text { Increased technician full-time equivalents devoted to } \\
\text { medication dispensing }\end{array}$ & $31.0 \quad(9)$ & 0.0 & $41.4 \quad(12)$ & 27.6 \\
\hline $\begin{array}{l}\text { Increased technician full-time equivalents devoted to patient } \\
\text { care services }\end{array}$ & 24.1 & 0.0 & $37.9 \quad(11)$ & 37.9 \\
\hline Targeted medication reviews & $39.3 \quad(11)$ & 0.0 & $(11)$ & 21.4 \\
\hline Educational pamphlets or printouts & $(2)$ & 0.0 & $62.1 \quad(18)$ & 31.0 \\
\hline Appointment-based medication synchronization & $44.8 \quad(13)$ & 0.0 & 24.1 & 31.0 \\
\hline Synchronized medication fills (nonappointment based) & $62.1(18)$ & 6.9 & 27.6 & 3.4 \\
\hline Blister/bubble packaging & $34.5 \quad(10)$ & 3.4 & $55.2 \quad(16)$ & 6.9 \\
\hline Disease state educational programming & 13.8 & 3.4 & 31.0 & 51.7 \\
\hline Collaborative practice agreements & 6.9 & 6.9 & 20.7 & 65.5 \\
\hline Comprehensive medication reviews & 58.6 & 0.0 & $(12)$ & 0.0 \\
\hline
\end{tabular}

Note: Total number of responses for each item ranged from 28 to 29.

"treating to the measure" and limiting quality improvement efforts for elements of care quality that are not directly related to included performance measures. Broader measures (e.g., measures that include multiple medications for chronic conditions ${ }^{30}$ ) may incentivize broader care improvement initiatives within pharmacies. Furthermore, if there is a possibility of financial gain, pharmacies may be more willing to engage than if the model contains only penalties. ${ }^{2}$

Finally, these models involve payments to pharmacies and not pharmacists. While this fits with the nature of the typical prescription payment stream, evidence from physician group practices suggests that incentives at the group level are not as effective as incentives at the provider level. ${ }^{2,4}$ In cases where bonuses are provided through these models, literature suggests that pharmacies and pharmacy chains should consider ways to channel bonuses to the pharmacists providing care for attributed patients. This may improve pharmacist engagement and reduce confusion. ${ }^{2,4}$

Despite their frustration, most participants reported implementing new services or expanding existing services in response to PBPPMs during the previous 12 months. The most common service, synchronized medication fills (appointment-based and nonappointment-based) has been shown to improve medication adherence and was likely implemented in response to adherence-related pressures from these models. ${ }^{31-35}$ Services such as telephone reminders to refill prescriptions, medication home delivery, and blister/bubble packing also targeted medication adherence and were newly implemented by $34.5 \%-44.8 \%$ of respondents. Other services, including comprehensive and targeted medication reviews, can identify gaps in care or unnecessary therapy, which can directly improve statin use in persons with diabetes, ACE-I/ARB in persons with diabetes and hypertension, and high-risk medication use in the elderly. This suggests that penalties from these models, while causing widespread frustration, is effective at producing positive changes in service offerings. While increased service offerings do not necessarily lead to improved outcomes, these changes suggest that improvement is possible and more work is needed to evaluate the effectiveness of PBPPMs at improving patient care.

\section{LIMITATIONS}

There are several notable limitations to this study. First, this study reported findings from only 42 pharmacy owners, 30 of whom completed most questions. A primary source of bias in this study was due to survey nonresponse and participant selection. Given that participants were selfselected, it is possible that only owners with purposeful intent participated in the survey. Therefore, these results are best interpreted as a series of case reports and may not 
be representative of the community pharmacists in general.

Second, community pharmacy owners, while having a closer view of business operations and greater control over services, may not be representative of staff pharmacists at independent pharmacies or pharmacists working at chain pharmacies who directly affect performance and quality through the provision of pharmacy and patient care services.

\section{Conclusions}

Results from this study found extensive confusion, frustration, and financial burden from PBPPMs. Despite this, many respondents indicated increased service offerings. Payers planning improvements to their models should consider ways to better engage and educate community pharmacists about model design, measure specifications, and cut-point determination. In addition, consideration could be given to creating opportunities for bonuses, as well as for penalties. For pharmacies, channeling bonuses to the pharmacist level may improve engagement. Finally, more research is needed regarding the effect of these models on patient care, as well as the relative effectiveness of any design changes.

\section{DISCLOSURES}

This work was supported by a grant from the American Association of Colleges of Pharmacy, which was not involved in the collection, analysis, and interpretation of data; writing of the report; or the decision to submit this article for publication. Urick reports consulting fees from Pharmacy Quality Solutions. The other authors declare no conflicts of interest with respect to the research, authorship, and/or publication of this article.

\section{ACKNOWLEDGMENTS}

The authors thank the National Community Pharmacy Association for its helpful suggestions during survey design and its support during survey administration. The authors also acknowledge funding support received from the American Association of Colleges of Pharmacy.

\section{REFERENCES}

1. Centers for Medicare \& Medicaid Services. Quality payment program. 2018. Accessed February 5, 2021. https://qpp. cms.gov/

2. Conrad DA. The theory of value-based payment incentives and their application to health care. Health Serv Res. 2015;50(Suppl 2):2057-89.

3. Pharmacy Quality Solutions. Website. 2020. Accessed February 5, 2021. https:// www.pharmacyquality.com/

4. Heider AK, Mang H. Effects of monetary incentives in physician groups: a systematic review of reviews. Appl Health Econ Health Policy. 2020;18(5):655-67.

5. Kondo KK, Damberg CL, Mendelson A, et al. Implementation processes and pay for performance in healthcare: a systematic review. J Gen Intern Med. 2016;31(Suppl 1):61-69.

6. Petersen LA, Simpson K, Pietz K, et al. Effects of individual physician-level and practice-level financial incentives on hypertension care: a randomized trial. JAMA. 2013;310(10):1042-50.

7. Bardach NS, Wang JJ, De Leon SF, et al. Effect of pay-for-performance incentives on quality of care in small practices with electronic health records: a randomized trial. JAMA. 2013;310(10):1051-59.

8. Asch DA, Troxel AB, Stewart WF, et al. Effect of financial incentives to physicians, patients, or both on lipid levels: a randomized clinical trial. JAMA. 2015;314(18):1926-35.

9. Mendelson A, Kondo K, Damberg C, et al. The effects of pay-for-performance programs on health, health care use, and processes of care: a systematic review. Ann Intern Med. 2017;166(5):341-53.
10. Vlaanderen FP, Tanke MA, Bloem BR, et al. Design and effects of outcomebased payment models in healthcare: a systematic review. Eur J Health Econ. 2019;20(2):217-32.

11. Landon B, O'Malley J, McKellar R, Reschovsky J, Hadley J. Physician compensation strategies and quality of care for Medicare beneficiaries. Am J Manag Care. 2014;20(10):7.

12. Frier Levitt. White paper: PBM DIR fees costing Medicare and beneficiaries: investigative white paper on background, cost impact, and legal issues. February 2, 2017. Accessed February 5, 2021. https://www.frierlevitt.com/articles/ pharmacylaw/white-paper-pbm-dirfees-costing-medicare-beneficiariesinvestigative-white-paper-backgroundcost-impact-legal-issues/

13. Modernizing Part D and Medicare Advantage to Lower Drug Prices and Reduce Out-of-Pocket Expenses. Fed Reg. 2018;83(231):62152-201. Accessed February 5, 2021. https://www.govinfo.gov/content/pkg/FR-2018-11-30/ pdf/2018-25945.pdf

14. Fein AJ. Pharmacy DIR fees hit a record $\$ 9$ billion in 2019-that's $18 \%$ of total Medicare Part D rebates. Drug Channels. February 13, 2020. Accessed February 5, 2021. https://www.drugchannels. net/2020/02/pharmacy-dir-fees-hitrecord-9-billion.html

15. Deninger MJ. DIR fees are not pay for performance. The Thriving Pharmacist. August 30, 2016. Accessed February 5, 2021. http://www.thethrivingpharmacist.com/2016/08/30/ dir-fees-are-not-pay-for-performance/

16. Harrington A. Evaluation of a community pharmacy pay-for-performance program [dissertation]. University of Arizona; 2016. Accessed February 5, 2021. https://search.proquest.com/ope nview/547e2804ae58635ffd21be386de5d 8bd/1.pdf?pq-origsite=gscholar \&cbl=187 50\&diss $=y$

17. Urick B, Trygstad T, Farley JF. Patient outcomes from implementing an enhanced services pharmacy network. J Am Pharm Assoc (2003). 2020;60(6): 843-852.e15. 
18. Centers for Medicare \& Medicaid Services. RE: CMS-4182-P-Medicare Program: Contract Year 2019 Policy and Technical Changes to the Medicare Advantage, Medicare Cost Plan, Medicare Fee-for-Service, the Medicare Prescription Drug Benefit Programs, and the PACE Program [press release]. National Community Pharmacists Association, January 16 2018. https://www.regulations.gov/ contentStreamer?documentId=CMS-2017$\underline{0156-1565 \& \text { attachmentNumber }=5 \& \text { conten }}$ tType=pdf

19. Actions of the 2018 APhA House of Delegates. J Am Pharm Assoc. 2018;58(4):355-65.

20. Actions of the 2017 APhA House of Delegates. J Am Pharm Assoc. 2017;57(4):442-52.

21. American Pharmacists Association. More than 240 patient, healthcare groups urge Congress to reform pharmacy "DIR fees" this year. May 8, 2020. Accessed February 5, 2021. https://www. pharmacist.com/press-release/more240-patient-healthcare-groups-urge-congress-reform-pharmacy-dir-fees-year

22. Ulrich CM, Danis M, Koziol D, Garrett-Mayer E, Hubbard R, Grady C. Does it pay to pay? A randomized trial of prepaid financial incentives and lottery incentives in surveys of nonphysician healthcare professionals. Nurs Res. 2005;54(3):178-83.

23. Teeter B. Quality performance in community pharmacies: an exploration of pharmacists' perceptions and predictors [dissertation]. Auburn University; 2015. Accessed February 5, 2021. https://etd. auburn.edu/xmlui/handle/10415/4859
24. Smith MG, Shea CM, Brown P, Wines K, Farley JF, Ferreri SP. Pharmacy characteristics associated with the provision of medication management services within an integrated care management program. J Am Pharm Assoc (2003). 2017;57(2):217-21.e1.

25. U.S. Bureau of Labor Statistics. Occupational Outlook Handbook. Pharmacists. October 13, 2020. Accessed February 5, 2021. https://www.bls.gov/ ooh/healthcare/pharmacists.htm

26. U.S. Bureau of Labor Statistics. Occupational Outlook Handbook. Pharmacy technicians. October 13, 2020. Accessed February 5, 2021. https://www. bls.gov/ooh/healthcare/pharmacy-technicians.htm

27. Osterberg L, Blaschke T. Adherence to medication. N Engl J Med. 2005; 353(5):487-97.

28. Renner HM, Hollar A, Stolpe SF, Marciniak MW. Pharmacist-to-prescriber intervention to close therapeutic gaps for statin use in patients with diabetes: a randomized controlled trial. J Am Pharm Assoc (2003). 2017;57(3 Suppl):S236-S242.e231.

29. Pharmacy Quality Solutions. Industry trend report in pharmacy quality. November 22, 2019. Accessed February 5, 2021. https://www.pharmacyquality. com/wp-content/uploads/2019/05/ PQSTrendReportinPharmacyQuality2019.pdf

30. Farley JF, Kumar A, Urick BY. Measuring adherence: a proof of concept study for multiple medications for chronic conditions in alternative payment models. Pharmacy (Basel). 2019;7(3):81.
31. Holdford D, Saxena K. Impact of appointment-based medication synchronization on existing users of chronic medications. J Manag Care Spec Pharm. 2015;21(8):662-69. doi: 10.18553/ jmcp.2015.21.8.662

32. Holdford DA, Inocencio TJ. Adherence and persistence associated with an appointment-based medication synchronization program. J Am Pharm Assoc (2003). 2013;53(6):576-83.

33. Krumme AA, Glynn RJ, Schneeweiss S, et al. Medication synchronization programs improve adherence to cardiovascular medications and health care use. Health Aff (Millwood). 2018;37(1):125-33.

34. Dao N, Lee S, Hata M, Sarino L. Impact of appointment-based medication synchronization on proportion of days covered for chronic medications. Pharmacy (Basel). 2018;6(2):44.

35. Witry M. Appointment-based models and medication synchronization: silver bullet for adherence or one piece of the puzzle? J Manag Care Spec Pharm. 2015;21(8):714. doi: 10.18553/ jmcp.2015.21.8.714 